\title{
Médiévales
}

Langues, Textes, Histoire

46 | printemps 2004

Éthique et pratiques médicales

\section{Maria Ginatempo, Prima del debito. Finanziamento della spesa pubblica e gestione del deficit nelle grandi città toscane $(1200-1350 \mathrm{ca})$}

Florence, Olschki (Biblioteca storica toscana, 38), 2000, 200 p.

Didier Boisseuil

\section{OpenEdition}

Journals

Édition électronique

URL : https://journals.openedition.org/medievales/1029

DOI : $10.4000 /$ medievales. 1029

ISSN : $1777-5892$

Éditeur

Presses universitaires de Vincennes

Édition imprimée

Date de publication : 1 juin 2004

Pagination : 145-146

ISBN : 2-84292-151-8

ISSN : 0751-2708

\section{Référence électronique}

Didier Boisseuil, « Maria Ginatempo, Prima del debito. Finanziamento della spesa pubblica e gestione del deficit nelle grandi città toscane (1200-1350 ca) », Médiévales [En ligne], 46 I printemps 2004, mis en ligne le 13 mars 2006, consulté le 29 avril 2022. URL : http://journals.openedition.org/medievales/1029 ; DOI : https://doi.org/10.4000/medievales. 1029

Ce document a été généré automatiquement le 29 avril 2022

Tous droits réservés 


\title{
Maria Ginatempo, Prima del debito. Finanziamento della spesa pubblica e gestione del deficit nelle grandi città toscane (1200-1350 ca)
}

Florence, Olschki (Biblioteca storica toscana, 38), 2000, 200 p.

\author{
Didier Boisseuil
}

1 Dans cet ouvrage court et dense, particulièrement bien documenté et précis, Maria Ginatempo nous propose une synthèse stimulante sur le financement des dépenses publiques, la gestion du déficit - et plus largement les finances - des principales communes urbaines de Toscane entre le XIII et le début du XIV siècle, au moment où elles se transforment en cités-États. Cette longue période de l'histoire financière urbaine - moins bien connue que la suivante, liée à l'apparition des monti, destinés à consolider la dette publique (à Florence en 1345, Pise en 1348, Sienne en 1363-1382, Lucques en 1371) - fut caractérisée par la mise en place d'un système fiscal complexe et le développement d'un endettement plus ou moins prononcé. Aussi, M. G. s'est-elle attachée à explorer les formes et les raisons de ce recours au crédit, en distinguant les singularités des différentes républiques et en établissant des comparaisons fructueuses avec d'autres cités du Nord de l'Italie (Gênes et Venise essentiellement).

2 Dans une première partie, M. G. revient sur le modèle classique - idéal-typique - de la cité-République que les historiens ont forgé et s'interroge sur la notion de dette publique permanente si communément admise. Elle rappelle que cette dette n'a pas vraiment existé avant la moitié du XIve siècle et que la dépense publique déficitaire (suscitée par des besoins financiers réguliers supérieurs aux entrées disponibles) était comblée, au coup par coup, par des prêts forcés et des prêts volontaires (suscitant un endettement communal), c'est-à-dire par des prélèvements qui touchaient l'épargne privée, obéraient les budgets des plus humbles. Elle constituait dès le XIII ${ }^{\mathrm{e}}$ siècle, dans les cités de Gênes et de Venise une dette régulière qui - sans être consolidée - était 
organisée institutionnellement, garantie par des rentrées fiscales indirectes, concédées aux créanciers (comme les gabelles à Gênes).

Dans une deuxième partie, M. G. explore la nature du déficit des communes urbaines pour souligner qu'il est essentiellement lié à des dépenses militaires, qu'il n'apparaît véritablement qu'à la fin du XIII ${ }^{\mathrm{e}}$ siècle, nécessitant des mesures fiscales nouvelles. Au cours du Duecento, la plupart des dépenses liées à la gestion du contado étaient assumées par les communes rurales et les cités n'assuraient que la sécurité et l'ordre public. Ces dernières connaissaient un déficit structurel acceptable, compensé par des impôts directs pesant sur les citoyens. Ce n'est que dans les années 1280-1290, alors que les contadi s'étendaient et que les modes de contrôle citadins s'accentuaient que l'on observe des besoins nouveaux, suscitant le recours à des solutions comparables à celles communément admises pour distinguer les cités-États classiques: renoncement à l'impôt direct qui devient exceptionnel, recours au prêt forcé pour les citoyens, établissement d'un prélèvement tributaire sur les comitatini ou les sottoposti (une somme fixe en échange de la securitas) et déploiement d'une fiscalité indirecte. Ce système fiscal qui se mit en place permit de faire face à l'extension des dépenses et le déficit resta acceptable jusqu'à ce que la conjoncture économique et démographique s'inverse, que les transformations opérées dans la façon de faire la guerre provoquent un surcoût, dans les années 1340 .

Dans une troisième partie, M. G. revient sur le mode de financement de ce déficit entre les années 1280-1340, en établissant une typologie des moyens déployés par les cités et souligne alors l'importance de l'endettement des cités-État auprès des citoyens que ce soit par le biais des prêts forcés ou de prêts volontaires (mutui) à court et moyen terme. Elle en vient à bousculer quelques idées reçues. D'abord elle précise l'importance des impositions indirectes et souligne combien l'affermage des gabelles n'était pas - pour ces cités - un moyen d'alléger la dette publique - comme c'était le cas dans plusieurs royaumes européens - mais une forme de gestion des recettes, les fermiers n'étant pas des créanciers de la commune. Ensuite, elle réévalue le rôle des estimes que certaines cités établirent comme mode d'évaluation des capacités fiscales des différents contribuables - comme à Sienne la tavola delle possessioni-, pour des prélèvements extraordinaires (sous la forme de dazia ou de libra), c'est-à-dire des impôts directs ou des prêts forcés. Elle en profite pour montrer que l'on a peine à en mesurer le montant de ces rentrées et que l'on peut au mieux apprécier leur fréquence, plus importante à Sienne ou à Pise qu'à Florence.

De même, elle souligne la place dans les budgets communaux des emprunts (prestanze) onéreux contractés auprès des citoyens les plus riches (surtout des magnats) fortement intégrés à la société citadine et gagés sur des biens fonciers ou des revenus liés à des droits seigneuriaux (à Sienne), miniers (à Pise). Elle s'attarde enfin, sur toutes les taxations indirectes qui, avant les années 1330, ont probablement moins pesé sur les produits de consommation courante qu'on ne l'imagine, dont l'augmentation fut insoutenable après 1340 et qui, étendues au contado, supplantèrent parfois les tributs des communes rurales (pour Sienne notamment). Ces quelques aspects distinguent les cités de Toscane des autres cités italiennes (Venise particulièrement qui connaissait dès le XIII ${ }^{\mathrm{e}}$ siècle un endettement permanent) et des États monarchiques ou princiers qui aliénèrent les revenus domaniaux et pratiquèrent la vénalité des offices (au profit parfois des banquiers toscans). 
6 Dans une quatrième partie, M. G. compare les différentes cités, trace les évolutions de leur système de financement du déficit. Elle retient essentiellement leur attachement aux prêts volontaires à court terme et surtout le développement des prêts forcés autour de 1300, d'abord prévu comme une avance faite au Trésor à valoir sur les prélèvements fiscaux ultérieurs, puis comme des prêts rétribués, dotés d'intérêts garantis par les gabelles, devenant, en fin de période des titres négociables. C'est alors, et alors seulement, que se forma une dette publique permanente en liaison avec les dépenses militaires croissantes, Florence initiant le processus. 